\title{
Limitations of faecal chymotrypsin as a screening test for chronic pancreatitis
}

\author{
L Riedel, A R P Walker, I Segal, A E Mohamed, A E Smyth, B Daya, I Naik
}

\begin{abstract}
Faecal chymotrypsin was measured in patients with chronic pancreatitis and in healthy black urban and rural control subjects. In the patients, significantly lower values of faecal chymotrypsin were obtained (mean (SD) 2.4 $1.79 \mathrm{U} / \mathrm{g}$ stool) whereas in urban control subjects, values were within the normal range (mean (SD) 13.2 (11.9)). In rural black control subjects, however, the faecal chymotrypsin value was significantly lower (mean (SD) $7 \cdot 1$ $(5 \cdot 1)$ ) than in urban black control subjects. It is suggested that faecal pH may influence faecal chymotrypsin values. The mean faecal $\mathrm{pH}$ in rural black subjects (pH 6.14) was significantly lower than that in urban control subjects (pH 6.77) and in patients with chronic pancreatitis (pH 6.61). Moreover, mean faecal chymotrypsin is high $(20.0 \mathrm{U} / \mathrm{g}$ stool) at a $\mathrm{pH}$ greater than 7. Between pH 6 and 7 the mean value drops to 8.6 U/g stool and below pH 6 mean faecal chymotrypsin is in the abnormal range (4.4 U/g stool). Hence, low values for faecal chymotrypsin may be due to lower faecal pH (less than 6) in healthy control subjects. For diagnostic purposes, the faecal pH value should be determined if a low faecal chymotrypsin value is obtained.
\end{abstract}

Faecal chymotrypsin determination in random stool samples is widely accepted as a valuable screening method to detect exocrine pancreatic insufficiency. ${ }^{1-5} \mathrm{~A}$ low faecal chymotrypsin value suggests a diagnosis of chronic pancreatitis. The method is insensitive in minor degrees of pancreatic dysfunction where intubation tests using secretin and pancreozymin are superior. ${ }^{125}$ Abnormally low faecal chymotrypsin values were found in only approximately $7 \%$ of normal subjects, ${ }^{4}$ indicating a high specificity of this method. One study, however, performed in Uganda, ${ }^{6}$ showed an appreciable overlap of faecal chymotrypsin values in patients with pancreatitis and control subjects. Dilution of the enzyme due to large stool volume was suggested as an explanation, but this was rejected by others. ${ }^{235}$

The aim of this study was to determine whether facecal chymotrypsin measurement in spot stool samples is a valuable screening method in the diagnosis of chronic pancreatitis in the black population in South Africa - a population in whom diets and disease patterns differ from those of western populations.

\section{Patients}

Faecal chymotrypsin activity was assessed in $\mathbf{3 0}$ outwardly healthy urban adults from Soweto, 30 healthy rural adults from villages in Western
Transvaal, and 16 patients with chronic pancreatitis from Soweto. All patients with chronic pancreatitis were men, whereas the male to female ratio in urban and rural black control subjects was $1: 1$. The mean age of patients with chronic pancreatitis was 38 years, of urban control subjects 29 years, and of rural control subjects 28 years. The diagnosis of chronic pancreatitis was confirmed by pancreatic function tests using secretin and pancreozymin and by endoscopic retrograde cholangiopancreatographic findings: volume, bicarbonate, and amylase output values were abnormal in all patients. In addition severe ductal changes were present in all patients and calcifications in eight. Both urban and rural control subjects were outwardly healthy. They had no symptoms suggestive of disease and did not drink alcohol. In particular, there were no symptoms of malnutrition. As to the possibility of the rural control subjects having undiagnosed pancreatitis, this is thought to be unlikely. From enquiries into causes of admissions to rural hospitals, admissions for pancreatitis are extremely rare. Some of these hospitals have facilities for the diagnosis of pancreatitis. It was thought that it was unethical to subject the control subjects to investigations for pancreatitis.

\section{Methods}

Faeces were passed in the morning and samples were brought the same morning to a collection centre where they were put on ice and transported to Baragwanath Hospital. The $\mathrm{pH}$ values were measured within six hours of collection. The samples were then deep frozen and faecal chymotrypsin was measured within 10 days. There was no difference in the time lapse between collection and measurement among urban and rural control subjects.

Altogether $100 \mathrm{mg}$ of crude stool were measured in sample preparation tubes (Boehringer Mannheim, cat no 745804). Some $10 \mathrm{ml}$ of solvent (cat no 718238) were added to the tubes and the samples were homogenised for two minutes with a vortex mixer. The homogenate was then centrifuged for five minutes and the supernatant used for the assay. Faecal chymotrypsin activity was determined in Tris buffer, pH 9, using Succ-Ala-Ala-Pro-Phe-pnitroaniline as substrate (Monotest Chymotrypsin, Boehringer Mannheim $\mathrm{GmbH}$ Diagnostica, Cat No 718211)..$^{78}$ During the test reaction p-nitroaniline is formed and is subsequently measured by reading absorbance at $405 \mathrm{~nm}$ on a Beckman Model 42 clinical analyser at $30^{\circ} \mathrm{C}$.

The reference values provided with the kit are as follows: the reference standard of the test is 
$8 \cdot 1 \mathrm{U} / \mathrm{g}$ stool (range $7 \cdot 0-9 \cdot 2$ ); normal range, faecal chymotrypsin more than $8.4 \mathrm{U} / \mathrm{g}$ stool; abnormal range, faecal chymotrypsin less than $4.2 \mathrm{U} / \mathrm{g}$ stool; further investigations are recommended when values are in the range between 4.2 and $8.4 \mathrm{U} / \mathrm{g}$ stool. In our region, however, it has been established that the normal range is above $5 \mathrm{U} / \mathrm{g}$ stool. ${ }^{9}$

The faecal pH value was determined using a Beckman Model 3500 digital pH meter, by examining an emulsion of $1 \mathrm{~g}$ faeces in $10 \mathrm{ml}$ isotonic saline. The $\mathrm{pH}$ of isotonic saline was $6 \cdot 25$. The electrodes were cleaned with distilled water and filter paper between each measurement and standardised after three measurements, and for each session of examinations the reading of the apparatus was checked against a buffer solution of $\mathrm{pH} 7 \cdot 00$.

\section{STATISTICAL ANALYSIS}

Analysis of the data was carried out using the Biomedical Computer Program P-series 1987 (University of California Press), BMPD, and the Statistical Analysis Systems (SAS Institute INC). Differences between the groups were assessed by the Student's $t$ test. To confirm the assumptions of the $t$ test, the logs of the faecal chymotrypsin values were taken to correct for skewness. The Bonferroni adjustment was made for multiple comparisons. Pearson's correlation coefficient was used to determine the correlation between $\mathrm{pH}$ and faecal chymotrypsin.

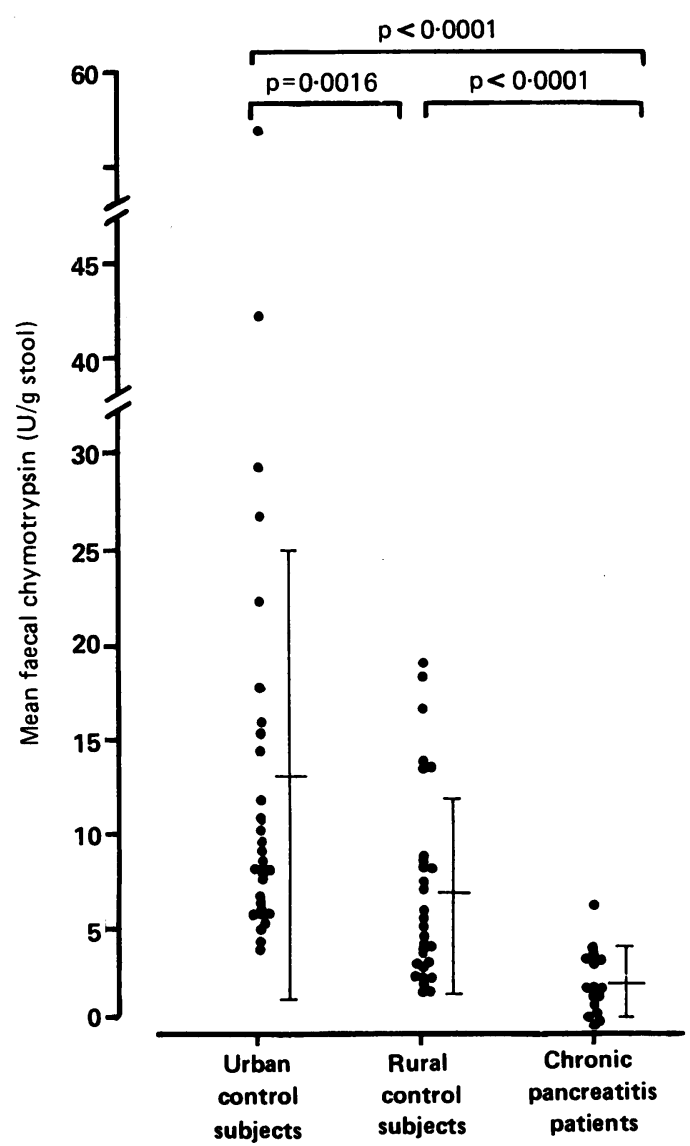

Figure 1: Individual faecal chymotrypsin values in patients with chronic pancreatitis $(C P)$, rural black control subjects $(R B)$ and urban black control subjects $(U B)$. Mean $(S D)$ faecal chymotrypsin values.
Mean faecal chymotrypsin (FCT) in combined rural and urban control subjects at three different $p H$ ranges

\begin{tabular}{llcl}
\hline pH range & $\begin{array}{l}\text { No of } \\
\text { subjects }\end{array}$ & Mean $(S D) F C T$ & $p$ \\
\hline pH $<6$ & 14 & $4 \cdot 4(2 \cdot 5)$ & 0.0036 \\
pH 6-7 & 32 & $8 \cdot 6(4 \cdot 3)$ & $0 \cdot 0009$ \\
pH $>7$ & 12 & $20 \cdot 0(15 \cdot 8)$ & \\
\hline
\end{tabular}

\section{Results}

\section{FAECAL CHYMOTRYPSIN}

Mean (SD) faecal chymotrypsin values plus individual values for patients with chronic pancreatitis and urban and rural control subjects are shown in Figure 1. In pancreatitis patients faecal chymotrypsin ranged from 0.2 to $6.8 \mathrm{U} / \mathrm{g}$ stool with a mean of $2 \cdot 4 \mathrm{U} / \mathrm{g}$ stool. Urban control subjects have a mean value of $13 \cdot 2 \mathrm{U} / \mathrm{g}$ stool (range from 4.0 to 56.8 ). In rural control subjects, faecal chymotrypsin was in the range 1.9 to 19.4 $\mathrm{U} / \mathrm{g}$ stool with a mean of $7 \cdot 1$. Rural control subjects have significantly lower mean faecal chymotrypsin than urban control subjects $(\mathrm{p}=$ 0.0016), but both urban and rural control subjects have significantly higher mean values than pancreatitis patients ( $p$ less than 0.0001 ). Thus $50 \%$ of rural blacks were in the pathologic range, compared to $6 \%$ of urban blacks and $93.8 \%$ of patients with chronic pancreatitis.

FAECAL PH

Urban control subjects and pancreatitis patients have very similar mean $\mathrm{pH}$ values 6.77 (range $5 \cdot 1-8$ ) and $6 \cdot 61$ (range 5.0-7.5) respectively. Moreover, the $\mathrm{pH}$ values are significantly higher than in rural control subjects who had a mean $\mathrm{pH}$ of $6 \cdot 14$ (range $5 \cdot 0-7 \cdot 6$ ). The Table shows mean faecal chymotrypsin at three different $\mathrm{pH}$ ranges

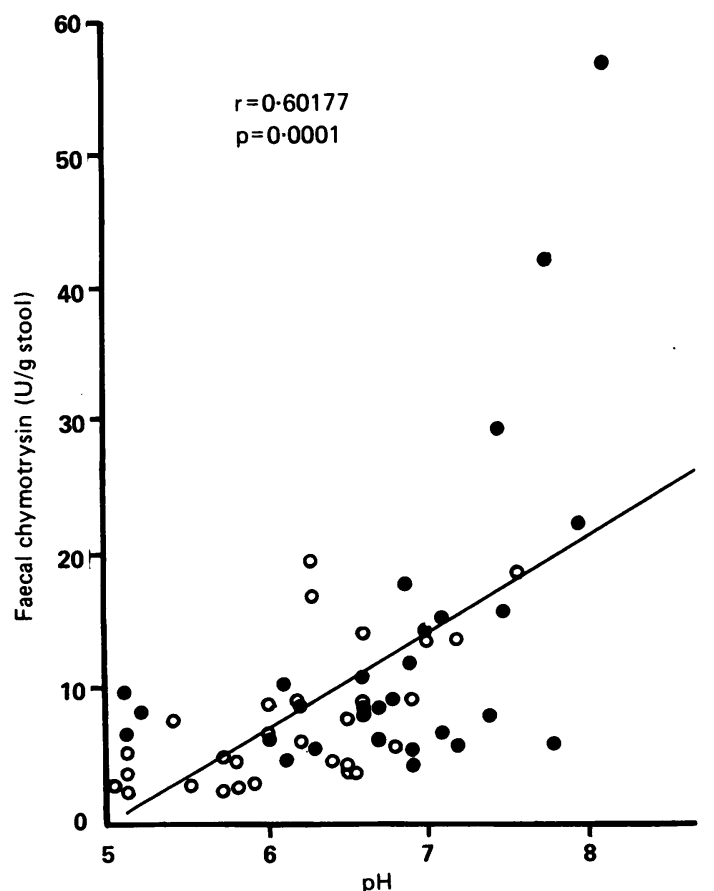

Figure 2: Correlation between faecal chymotrypsin and $\mathrm{pH}$ of faeces of rural $(\mathrm{O})$ and urban $(\mathrm{O})$ control subjects. The regression line shown is calculated for urban and rural control subjects combined. 


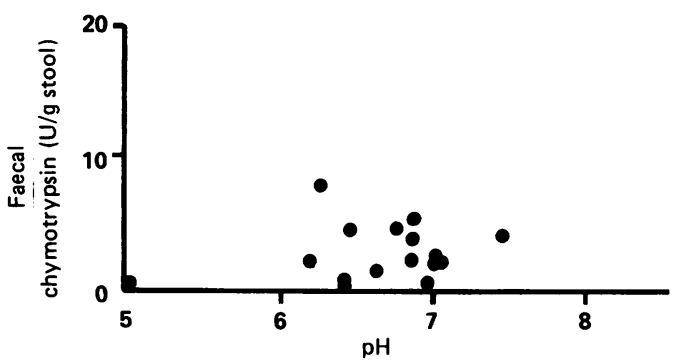

Figure 3: Relation between faecal chymotrypsin and $p H$ of faeces in patients with chronic pancreatitis. No significant correlation was found between the two.

in rural and urban control subjects combined. At a pH of less than 6 mean faecal chymotrypsin was $4.4 \mathrm{U} / \mathrm{g}$ stool, at $\mathrm{pH}$ between 6 and 7 it was 8.6 $\mathrm{U} / \mathrm{g}$ stool, and at $\mathrm{pH}$ of more than 7 the mean value was $20.0 \mathrm{U} / \mathrm{g}$ stool. The difference between faecal chymotrypsin in subjects at the three different $\mathrm{pH}$ ranges is statistically highly significant.

In Figure 2, faecal chymotrypsin is plotted against faecal $\mathrm{pH}$ in rural and urban control subjects. The correlation between faecal chymotrypsin and $\mathrm{pH}$ is highly significant $(\mathrm{r}=+0.602$; $p=0.0001$ ). (Urban control subjects $r=+0.559$; $p=0.0016$. Rural control subjects $r=+0.617$; $p=0.0004)$. The two regression lines differ only slightly from each other. In Figure 3 faecal chymotrypsin is plotted against faecal $\mathrm{pH}$ in patients with chronic pancreatitis. No significant correlation between the two parameters was found in this group.

There were no significant differences in faecal chymotrypsin and faecal $\mathrm{pH}$ between men and women in the two control groups.

To our knowledge there are no data available on faecal $\mathrm{pH}$ values of rural patients with chronic pancreatitis. In fact there are very limited data on pancreatitis in rural dwellers. Until recently, alcohol intake has been relatively low in this community.

\section{Discussion}

The efficacy of faecal chymotrypsin in the diagnosis of chronic pancreatitis is confirmed in the black patients with this disease when compared with urban control subjects. However, $50 \%$ of subjects in the rural control group had values in the abnormal range and had significantly lower faecal chymotrypsin values than urban control subjects. It is not known what the difference is between rural control subjects with normal and abnormal faecal chymotrypsin, except for faecal $\mathrm{pH}$ values. Rural subjects with abnormal faecal chymotrypsin (less than $5 \mathrm{U} / \mathrm{g}$ stool) had a mean faecal $\mathrm{pH}$ of 5.76 and those with normal values had a mean faecal $\mathrm{pH}$ of 6.50. All control subjects were categorised as being in every day good health.

The faecal concentration of chymotrypsin is reported to depend on two factors: the pancreatic enzyme secretion into the duodenum, and the enzyme inactivation during intestinal passage. ${ }^{2}$ Rapid transit allows for less inactivation of the enzyme and therefore a higher activity of chymotrypsin in faeces is recovered. Intestinal transit is more rapid in rural than in urban black sub- jects. ${ }^{10-12}$ Pancreatic enzyme secretion from a normal pancreas can theoretically be modified by diet. It has been shown in animal experiments that the output of proteolytic enzymes can be influenced by varying the protein content of the diet. ${ }^{13} \mathrm{~A}$ low protein diet could be responsible for a decreased pancreatic output of chymotrypsin. However, the mean (SD) protein intake of the group was 67 (38) g; the recommended dietary allowance is $46-54 \mathrm{~g}$ daily. ${ }^{14}$ It was not possible to correlate significantly faecal chymotrypsin and individual protein intake in the control subjects studied.

Intestinal mechanisms have also been implicated in modifying faecal chymotrypsin activity. ${ }^{15-17}$ Intestinal motility and gut flora are thought to be of importance. Rural black subjects void larger stools than their urban counterparts and thus probably have a larger bacterial cell mass. ${ }^{18}$ The larger colonic bacterial cell mass in the rural population may lead to an appreciable breakdown of chymotrypsin during the passage through the colon.

It has been argued that the low faecal chymotrypsin activity may be due to large stool volume. ${ }^{6}$ A study from Uganda found a significant overlap of faecal chymotrypsin values in control subjects and patients with pancreatitis. ${ }^{6} \mathrm{~A}$ dilution effect was suggested to explain this, as it was shown that patients and control subjects with large volume stools had low faecal chymotrypsin values. Subsequent studies, however, could not confirm this relation and it is thought that dilution is of minor importance. ${ }^{23819}$ Because we had no data on the stool volume, faecal chymotrypsin and stool volume could not be correlated. In our study we found a similar degree of overlap in faecal chymotrypsin activity between pancreatitis patients and control subjects, as was found in the Ugandan study.

The low faecal chymotrypsin activity could also be attributed to failure of activation. Due to technical problems and the instability of the enzyme it was not possible to test samples for trypsin. Other possible explanations are inactivation by anti-chymotrypsin proteases as found, for example, in potatoes, and adsorption to food fibres and differences in bowel motility. In this regard there is a greatly decreased fibre intake in urban blacks - $14 \mathrm{~g}$ daily - compared with rural blacks, who consume $25-35 \mathrm{~g}$ of dietary fibre. ${ }^{20}$

It has been shown from in vitro investigations, that the enzymatic activity of faecal chymotrypsin is $\mathrm{pH}$ dependant. ${ }^{21}$ The $\mathrm{pH}$ optimum for chymotrypsin in faeces is between 8.5 and 9.5 and drops sharply below and above. We have shown a highly significant positive correlation between faecal chymotrypsin and faecal $\mathrm{pH}$ in healthy control subjects. Only when the pH was more than 6, was the mean faecal chymotrypsin in the normal range. It is suggested that there is a causal relationship between low $\mathrm{pH}$ and low faecal chymotrypsin activity. This hypothesis can only be verified in vivo, however, changing faecal $\mathrm{pH}$ by, for example, dietary methods. Pancreatic enzymes are thought to be more stable at a lower than a higher $\mathrm{pH}$, thus inactivation of the enzyme is unlikely to explain low faecal chymotrypsin values at a low faecal $\mathrm{pH}$. It is therefore suggested that degradation of chymotrypsin 
during the intestinal passage may occur yielding low values. Another possibility - that is, lesser enzyme secretion by rural blacks - cannot be excluded.

Faecal $\mathrm{pH}$ values are lower in rural black subjects, and to certain extent in urban black subjects, compared with white subjects. ${ }^{22}{ }^{23}$ It is therefore suggested that a low faecal $\mathrm{pH}$ could contribute or even be responsible for the low faecal chymotrypsin activities in rural black subjects, and that faecal $\mathrm{pH}$ should be determined when a low faecal chymotrypsin value is obtained. Accordingly a low faecal chymotrypsin at a low faecal pH should not be regarded as necessarily abnormal.

Studies were supported in part by a grant from the Nationa Cancer Association of South Africa and Medical Research Council of South Africa.

1 Lami FL, Callegari C, Miglioli M, Barbara L. A singlespecimen fecal chymotrypsin test in the diagnosis of pancreatic insufficiency: correlation secretin-cholecystokinin and NBT-PABA tests. Am $\mathcal{F}$ Gastroenterol 1984; 79: 697-

Ammann RW, Akovbiantz A, Haecki W, Largiader F, in pancreatic insufficiency, particularly chronic pancreatitis: in pancreatic insufficiency, particularly chronic pancreatitis: correlation with the pancreozymin-secretin test, fecal fat
excretion and final clinical diagnosis. Digestion 1981; 21: excretion.

3 Ammann RW, Tagwercher E, Kashiwag H, Rosenmund $H$ Diagnostic value of fecal chymotrypsin and trypsin assessment for detection of pancreatic disease. Am $\mathcal{F}$ Dig Dis 1968 13: $123-46$.

4 Duerr HK, Forell MM, Bode JC. Fecal chymotrypsin: a study on its diagnostic value by comparison with the secretincholecystokinin test. Digestion 1978; 17: 404-9

5 Gilat T, Gelman-Malachi E. Chymotrypsin output in the stools in pancreatic and other diseases. Am $\mathcal{F}$ Gastroenterol 1976; 66: $140-5$.
6 Banwell JG, Leonard PJ, Lobe RMF. Measurement of trypsin and chymotrypsin activity in stools to detect chronic pancreatic disease. Gut 1965; 6: 143-5.

7 DelMar EG, Largman C, Brodwick JW, et al. A sensitive new substrate for chymotrypsin. Anal Biochem 1979; 99: 316-20.

8 Bode C, Bode JC. Usefulness of a simple photometric determination of chymotrypsin activity in stools - results of a multicentre study. Clin Biochem 1986; 19: 333-7.

9 Personal Communication, J Aucamb, Medlab, Pretoria.

9 Personal Communication, J Aucamb, Medlab, Pretoria. bowel motility. $S$ Afr Med $\mathcal{F} 1947 ; 21: 590-6$.

11 Walker ARP, Walker BF, Richardson BD. Bowel transit times in Bantu populations. $B M F$ 1970; 3: 48-9.

12 Oettle GJ, Segal I. Bowel function in an urban black African population. Dis Colon Rectum 1985; 28: 717-20.

13 Wormsley KG, Goldberg DM. The interrelationships of the pancreatic enzymes. Gut 1972; 13: 398-412.

14 The National Research Council. Recommended dietary allowances. RDA. 9th revised Ed. Washington DC: National Academy of Sciences, 1980 .

15 Pelot D, Grossman M. Distribution and fate of pancreatic enzymes in small intestine of the rat. Am F Physiol 1962, 202: enzymes 8 .

16 Goldberg DM, Campbell R, Roy AD. Fate of trypsin and chymotrypsin in the human small intestine. Gut 1969; 10 . chymot $477-83$.

17 Sale JK, Goldberg DM, Thjodleifsson B, Wormsley KG. Trypsin and chymotrypsin in duodenal aspirate and faeces in response to secretin and cholecystokinin-pancreozymin. Gu 1974; 15: 132-8.

18 Burkitt DP, Walker ARP, Painter NS. Effect of dietary fibre on stools and transit times and its role in the causation of disease. Lancet 1972; ii: 1408-12.

19 Bode JC, Duerr HK. Bestimmung von chymotrypsin in stuh als suchtest fuer eine exocrine pancreasinsuffizienz. Dtsch Med Wochenschr 1977; 102: 165-6.

20 Segal I, Walker ARP. Low fat intake with falling fibre intake commensurate with rarity of noninfective bowel diseases in blacks in Soweto, Johannesburg, South Africa. Nutr Cancer 1986; 8: 185-91.

21 Duerr HK, Schneider R, Bode JC. Fecal chymotrypsin: study on some characteristics of the enzyme. Digestion 1978; 17 396-403.

22 Samuelson SL, Nelson RL, Nyhus LM. Protective role of faecal $\mathrm{pH}$ in experimental colon carcinogenesis. $\mathcal{F} R$ Soc Med 1985; 78: 230-3.

23 Walker ARP, Walker BF, Walker AJ. Faecal pH, dietary fibre intake, and proneness to colon cancer in four South African populations. Brf Cancer 1986; 53: 489-95. 